\title{
Side-to-side growth discrepancies in children with hemiplegic cerebral palsy: association with function, activity and social participation
}

\author{
Discrepâncias no crescimento dos dimídios em crianças com paralisia cerebral
} hemiplégica: associação com a função, atividades e participação social

Marise Bueno Zontaํ. Amâncio Ramalho-Júnior ${ }^{2,5}$, Marilene Puppi ${ }^{1}$, Isac Bruck ${ }^{3}$, Neiva Magdalena ${ }^{3}$, Sandra Regina B. Muzzolon', Arnolfo de Carvalho-Neto ${ }^{4}$, Lúcia H Coutinho dos Santos ${ }^{3}$

\begin{abstract}
Objective: Evaluate side-to-side discrepancies in children with hemiplegic cerebral palsy (HCP), and investigate associations of these discrepancies with patients' age at initiation of physical therapy, motor and cognitive function, and degree of activities and social participation. Method: We obtained eight side-to-side measurements from $24 \mathrm{HCP}$ children with mean age $49.3 \pm 5.2$ months. Results: Early initiation of physical therapy was associated with lower discrepancy in hand length $(p=0.037)$. Lower foot length discrepancy was associated with lower requirement for caregiver assistance in activities related to mobility. Increased side-to-side discrepancy was associated with reduced wrist extension and increased spasticity. Discrepancy played a larger role in children with hemineglect and in those with right involvement. Conclusion: Increased discrepancy in HCP children was associated with reduced degree of activity/social participation. These results suggest an association between functional use of the extremities and limb growth.
\end{abstract}

Keywords: children, cerebral palsy, hemiplegia, function, growth.

RESUMO

Objetivo: Avaliar a discrepância entre o crescimento dos lados do corpo em crianças com paralisia cerebral hemiplégica (PCH), e investigar sua associação com a idade de início do tratamento de fisioterapia, função motora e cognitiva, grau de atividades e participação social. Método: Comparamos oito medidas obtidas de 24 crianças com PCH e com média de idade de 49,3 $\pm 5,2$ meses. Resultados: 0 início precoce da fisioterapia se relacionou à menor discrepância no comprimento da mão $(p=0,037)$. A menor discrepância no comprimento do pé se relacionou à menor necessidade de ajuda do cuidador em atividades de mobilidade. A maior discrepância esteve relacionada à menor extensão de punho e à maior espasticidade. A discrepância foi mais importante em crianças com heminegligência e com envolvimento à direita. Conclusão: Crianças com PCH com maior discrepância apresentaram menor atividade/participação social. Os resultados sugerem associação entre o uso funcional da mão e o crescimento das extremidades.

Palavras-chave: paralisia cerebral, hemiplegia, crianças, crescimento, função.

In children with hemiplegic cerebral palsy (HCP), multiple factors associated with the brain injury itself, or with the presence of other comorbidities, can affect cognitive and motor function. According to Rosenbaum, "Impairment can vary considerably and no two people with cerebral palsy are affected in exactly the same way". One of the factors related to impaired function in these children is growth discrepancy on the affected (hemiplegic) side when compared with the unaffected (normal) side. This side-toside discrepancy affects the majority of HCP children ${ }^{2,3,4}$ and may be observed in particular by comparing the sizes of both hands ${ }^{4}$. This discrepancy also increases with age $e^{3,4}$, tends to be proportional between upper and lower limbs on the affected side $^{4}$, is accompanied by a delay in skeletal

${ }^{1}$ Centro de Neuropediatria, Hospital de Clínicas, Universidade Federal do Paraná, Curitiba PR, Brazil;

${ }^{2}$ Universidade Federal de São Paulo, Sao Paulo SP, Brazil;

${ }^{3}$ Departamento de Pediatria, Universidade Federal do Paraná, Curitiba PR, Brazil;

4Departamento de Clínica Médica, Universidade Federal do Paraná, Curitiba PR, Brazil;

${ }^{5}$ Hospital Albert Einstein, Sao Paulo SP, Brazil.

Correspondence: Marise Bueno Zonta; Centro de Neuropediatria, Hospital de Clínicas, Universidade Federal do Paraná; Rua Floriano Essenfelder, 81; 80060270 Curitiba PR, Brasil; E-mail: marisebzonta@gmail.com

Conflict of interest: There is no conflict of interest to declare.

Received 15 May 2013; Received in final form 20 December 2013; Accepted 16 January 2014. 
maturation and by muscular underdevelopment ${ }^{3,5,6}$, and is related to disease severity ${ }^{7}$. Some studies have reported an association between discrepancy and sensory deficits ${ }^{8}$ or motor function ${ }^{2,3}$, but not with degree of spasticity. In contrast, other factors, such as handedness, muscle strength, wrist extension range of motion, lower limb motor function, presence of hemineglect, cognitive function, degree of activity (such as carrying out tasks) and social participation (involvement in life situations) ${ }^{9}$ have not been addressed in previous studies.

The impairment in growth on the affected side has been attributed to neurotrophic factors associated with the endocrine system, immobility or lack of stimulation from weight bearing ${ }^{7,10}$. Stevensen et al. reported that a better understanding of the causes and mechanisms of growth impairment in HCP could lead to improved clinical care and contribute to better quality of life ${ }^{7}$. Some authors question if non-nutritional interventions, such as physical therapy and weight bearing, would not have a positive impact on linear growth ${ }^{11}$. Demir et al. suggest that extremity shortness can be controlled by comprehensive rehabilitation programs and reconstructive procedures that increase the function of the upper extremities, as well as the function of the hands ${ }^{3}$. The International Classification of Functioning, Disability and Health (ICF) model, proposed by the World Health Organization ${ }^{9}$, prioritizes functionality as a component of overall health and emphasizes that goals and outcomes should be related to activity and participation.

The objective of this study was to evaluate side-to-side discrepancies in children with HCP and investigate the association of such discrepancies with the child's age at initiation of physical therapy, motor and cognitive function, and degree of activities and social participation.

\section{METHOD}

This was a cross-sectional and descriptive study, carried out between June 2005 and August 2006. The study was approved by the Human Research Ethics Committee of Hospital de Clínicas of Universidade Federal do Paraná, (UFPR) Curitiba, Brazil. All parents signed a free and informed consent form to allow participation of their children in the study.

\section{Participants}

We recruited a convenience sample of HCP children attending the Pediatric Spasticity Outpatient Clinic at the Centro de Neuropediatria do Hospital de Clínicas of UFPR. Patients had ages ranging from 3 to 5 years, independent mobility and motor impairment classified as levels I and II according to the Gross Motor Function Classification System $(\mathrm{GMFCS})^{12}$.
The inclusion criterion was spastic hemiplegia due to cerebral palsy. None of the children who participated in the study had history of concomitant genetic, metabolic, or neurodegenerative diseases, or any other disorder with potential to affect growth.

\section{Outcome Measures}

We performed eight anthropometric measurements evaluating the sizes of both the affected and unaffected limbs: 1) upper and 2) lower limb total lengths, 3) hand and 4) foot lengths, 5) hand widths, and 6) arm, 7) thigh and 8) calf circumferences. The measurements followed standard criteria $^{13}$. Side-to-side discrepancies were calculated in centimeters and in percentages by comparing the affected and unaffected sides. Data were analyzed according to the formula adapted from Demir et al. ${ }^{3}$.

We further compared the obtained anthropometric measurements with clinical and functional data, including laterality of the deficit, muscle tone assessed by the Ashworth scale $^{14}$, and muscle strength ${ }^{15}$. The results obtained from muscle tone and strength assessments were grouped as suggested by Brown et al. ${ }^{16}$.

We used a goniometer drive to assess active and passive range of motion for wrist extension. Obtained values were assigned a score on the Upper Limb Physician's Rating Scale (UPRS) ${ }^{17}$, on the Gross Motor Function Measure - 88 $(\text { GMFM-88) })^{18}$ and on the Pediatric Evaluation of Disability Inventory (PEDI) ${ }^{19}$. With the GMFM- $88^{18}$ we assessed motor capacity and with the PEDI ${ }^{19}$ we evaluated motor performance in self-care and mobility, as well as level of caregiver assistance. The PEDI covers a broad domain of functioning, considering both the activity level and aspects of the participation level ${ }^{20}$.

Gait pattern was assessed using the Physician's Rating Scale (PRS) ${ }^{21}$, a recognized scale that scores various components of gait movement, yielding scores for each leg that range from zero to 14 . We also considered a TwoDimensional Gait Analysis using data retrieved from another study using the same cohort ${ }^{22}$.

We assessed the intelligence quotient (IQ) of each child using the Wechsler Preschool and Primary Scale of Intelligence-Revised (WPPSI-R) test ${ }^{23}$. The presence of hemineglect was assessed with the Wechsler Intelligence Scale for Children, fourth edition (WISC-IV) cancellation subtest ${ }^{23}$. We also considered in the analysis the average age of the children at initiation of physical therapy.

\section{Statistical analysis}

The Spearman correlation coefficient was applied to estimate the association between quantitative variables. To compare quantitative variables between two independent subgroups, we used either Student's $t$-test or MannWhitney nonparametric test, as appropriate. Fisher's exact 
test was used to compare dichotomous nominal variables and Student's $t$-test was applied to analyze dependent variables. A p value below 0.05 was considered statistically significant. All analyses were performed using Statistica ${ }^{\mathbb{R}}$ 5.1 (StatSoft, Tulsa, Okla.).

\section{RESULTS}

Twenty-four HCP children with mean age of $49.3 \pm 5.2$ months (range 39-60 months) participated in the study. There was a predominance of males $(n=19 ; 79 \%)$ and left side involvement $(\mathrm{n}=13 ; 54 \%)$. Detailed data for each child are provided in Table 1.

All children presented shortening of the affected side on at least three measurements. Similarly, the averages of all measurements of length, width and circumference were significantly lower on the affected side when compared with the unaffected side $(p<0.001)$. The greatest discrepancies were observed on the length and width of the palms of the hands. Detailed anthropometric data are shown in Tables 2 and 3.

As discrepancies in total upper limb length decreased, passive and active extension of the wrist increased
( $\mathrm{p}=0.021$ and $\mathrm{p}=0.006$, respectively). In contrast, increased muscle tone in the affected upper limb was associated with increased discrepancies in total upper limb length $(\mathrm{p}=0.001)$, hand length $(\mathrm{p}=0.002)$ and palm width $(\mathrm{p}=0.023)$.

A comparison between sides showed significant differences in proximal, distal and total muscle strength for both upper and lower limbs, with the exception of proximal lower limb strength which did not show significant differences between sides. When compared with the unaffected side, the greatest decrease in strength on the affected side occurred in the upper distal limb muscles $(83 \%$ of the normal side), followed by the lower limb distal muscles $(85 \%$ of the normal side). Comparing side-to-side discrepancies in muscle strength between the upper and lower limbs, we found that the greatest decrease in muscle strength was in the upper limb, with an average of $86 \%$ of the strength of the unaffected side, while in the lower limb, the average was $94 \%$. Table 4 shows the correlations between the discrepancies and muscle strength.

Gross motor function mean total score was $93 \pm 12 \%$. A higher GMFM-88 score was associated with lower discrepancies in foot length. In addition, both UPRS and GMFM88 scores increased as the discrepancies in the measurements of the upper limb decreased (Table 4).

Table 1. Individual characteristics of study participants.

\begin{tabular}{|c|c|c|c|c|c|c|c|c|c|c|c|c|c|c|c|}
\hline $\begin{array}{l}\text { Patient } \\
\text { ID }\end{array}$ & $\mathrm{G}$ & Side & Age & $\begin{array}{l}\text { Gest age } \\
\text { (weeks) }\end{array}$ & $\begin{array}{l}\text { Weight } \\
\text { at birth }\end{array}$ & $\begin{array}{l}\text { Adverse } \\
\text { events }\end{array}$ & Epilepsy & $\begin{array}{c}\text { GMFCS } \\
\text { level }\end{array}$ & $\begin{array}{l}\text { GMFM } \\
\text { T score }\end{array}$ & IQP & VIQ & $\mathrm{TIQ}$ & PRS & UPRS & Neuroimage \\
\hline 1 & M & L & 41 & term & AGA & No & Yes & I & $81.0 \%$ & 47 & 52 & 45 & 14 & 18 & 1 \\
\hline 2 & M & $L$ & 41 & term & AGA & Yes & Yes & I & $94.1 \%$ & 49 & 63 & 52 & 13 & 18 & 1 \\
\hline 3 & M & $\mathrm{R}$ & 41 & term & AGA & Yes & No & $\|$ & $58.5 \%$ & 74 & 91 & 81 & 13 & 6 & 4 \\
\hline 4 & M & $\mathrm{R}$ & 55 & term & LGA & Yes & No & I & $98.3 \%$ & 79 & 84 & 80 & 14 & 16 & 2 \\
\hline 5 & $\mathrm{~F}$ & $\mathrm{R}$ & 48 & preterm (32) & AGA & Yes & No & I & $93.8 \%$ & 51 & 67 & 56 & 14 & 23 & 2 \\
\hline 6 & M & $L$ & 53 & term & AGA & Yes & No & I & $97.0 \%$ & 65 & 88 & 74 & 10 & 16 & 3 \\
\hline 7 & M & $L$ & 45 & $\begin{array}{c}\text { preterm } \\
(341 / 2)\end{array}$ & SGA & Yes & No & 1 & $94.7 \%$ & 77 & 87 & 77 & 10 & 10 & 2 \\
\hline 8 & M & $\mathrm{L}$ & 55 & term & AGA & No & No & 1 & $93.2 \%$ & 94 & 105 & 99 & 14 & 26 & 5 \\
\hline 9 & M & $\mathrm{L}$ & 46 & term & AGA & Yes & No & I & $95.0 \%$ & 58 & 81 & 67 & 12 & 17 & 3 \\
\hline 10 & $\mathrm{~F}$ & $L$ & 38 & term & AGA & Yes & No & I & $92.0 \%$ & 82 & 95 & 88 & 12 & 21 & 2 \\
\hline 11 & $\mathrm{~F}$ & $L$ & 39 & preterm (26) & AGA & Yes & Yes & I & $93.0 \%$ & 106 & 95 & 101 & 12 & 19 & 1 \\
\hline 12 & M & $\mathrm{L}$ & 40 & preterm (26) & AGA & Yes & No & I & $92.5 \%$ & 47 & 50 & 44 & 13 & 22 & 3 \\
\hline 13 & M & $\mathrm{L}$ & 39 & term & AGA & No & No & I & $92.0 \%$ & 126 & 119 & 126 & 8 & 20 & 2 \\
\hline 14 & M & $\mathrm{L}$ & 51 & term & AGA & No & No & $\|$ & $53.0 \%$ & 47 & 48 & 43 & 9 & 7 & 4 \\
\hline 15 & M & $\mathrm{R}$ & 41 & term & AGA & No & No & I & $90.3 \%$ & 98 & 99 & 98 & 10 & 17 & 2 \\
\hline 16 & $\mathrm{~F}$ & $\mathrm{R}$ & 39 & term & AGA & No & No & 1 & $93.0 \%$ & 55 & 74 & 61 & 12 & 24 & 1 \\
\hline 17 & M & $\mathrm{R}$ & 45 & term & LGA & Yes & No & 1 & $86.0 \%$ & 71 & 79 & 72 & 13 & 11 & 2 \\
\hline 18 & M & $\mathrm{R}$ & 53 & term & AGA & Yes & No & 1 & $96.0 \%$ & 89 & 100 & 94 & 14 & 24 & 2 \\
\hline 19 & M & $\mathrm{R}$ & 46 & term & AGA & Yes & No & I & $72.0 \%$ & 74 & 81 & 76 & 11 & 11 & 3 \\
\hline 20 & M & $\mathrm{R}$ & 41 & preterm (*) & $(\star)$ & Yes & No & I & $85.6 \%$ & 48 & 61 & 50 & 14 & 23 & 1 \\
\hline 21 & M & $\mathrm{R}$ & 58 & term & AGA & No & No & I & $95.6 \%$ & 77 & 112 & 94 & 13 & 23 & 1 \\
\hline 22 & M & $L$ & 50 & preterm (27) & AGA & Yes & No & I & $80.2 \%$ & * & * & * & 13 & 18 & 4 \\
\hline 23 & $\mathrm{~F}$ & $\mathrm{R}$ & 41 & term & AGA & No & No & I & $95.0 \%$ & 77 & 92 & 83 & 7 & 22 & 1 \\
\hline 24 & M & $\mathrm{L}$ & 53 & term & AGA & Yes & No & 1 & $96.0 \%$ & 115 & 152 & 141 & 14 & 15 & 2 \\
\hline
\end{tabular}

G: gender; M: masculine; F: feminine; Side: side of involvement: L: left; R: right; Age: age (months) of evaluation; Gest age: gestational age; AGA: adequate for gestational age; LGA: large for gestational age; SGA: small for gestational age; Adverse events: presence of adverse events at birth; Epilepsy: presence of epilepsy; GMFCS level: gross motor function classification level; GMFM T score: total score in the gross motor function measure; IQP: score for intelligent quotient performance; VIQ: verbal intelligent quotient score; TIQ: total intelligent quotient score; PRS: physician's rating scale score; UPRS: upper limb physician's rating scale score; Neuroimage: neuroimage classification: 1: maldevelopment; 2: periventricular atrophy; 3: cortical/subcortical atrophy, 4: miscellaneous; 5: normal. *Data not obtained. 
Table 2. Comparison of measurements obtained on the affected (hemiplegic) and unaffected sides $(n=24)$.

\begin{tabular}{|c|c|c|c|c|c|}
\hline Measurements (in cm) & $\begin{array}{l}\text { Unaffected side } \\
\text { mean (SD) }\end{array}$ & $\begin{array}{l}\text { Affected side } \\
\text { mean (SD) }\end{array}$ & Mean difference & $\begin{array}{c}\text { Mean \% } \\
\text { difference }\end{array}$ & $p$ value \\
\hline Upper limb total length & $44.29( \pm 2.79)$ & $43.06( \pm 2.68)$ & $1.22( \pm 0.94)$ & 2.65 & $<0.001$ \\
\hline Hand length & $11.76( \pm 0.72)$ & $10.89( \pm 0.76)$ & $0.88( \pm 0.54)$ & 6.1 & $<0.001$ \\
\hline Hand width & $6.06( \pm 0.26)$ & $5.70( \pm 0.45)$ & $0.36( \pm 0.34)$ & 5.99 & $<0.001$ \\
\hline Lower limb total length & $45.17( \pm 2.17)$ & $44.52( \pm 2.19)$ & $0.65( \pm 0.65)$ & 1.5 & $<0.001$ \\
\hline Foot length & $16.33( \pm 0.81)$ & $15.59( \pm 0.89)$ & $0.73( \pm 0.56)$ & 4.41 & $<0.001$ \\
\hline Arm circumference & $18.04( \pm 1.16)$ & $16.88( \pm 1.06)$ & $1.12( \pm 0.57)$ & 5.75 & $<0.001$ \\
\hline Thigh circumference & $32.19( \pm 2.30)$ & $31.23( \pm 2.45)$ & $0.88( \pm 0.63)$ & 2.68 & $<0.001$ \\
\hline Calf circumference & $21.81( \pm 1.32)$ & $20.93( \pm 1.35)$ & $0.88( \pm 0.53)$ & 2.65 & $<0.001$ \\
\hline
\end{tabular}

SD: standard deviation.

Lower discrepancies in foot length were also associated with greater independence in the PEDI mobility scale and in the PEDI Caregiver Assistance scale (Table 4) and with better scores in the PRS $(\mathrm{p}=0.047)$. There was a trend toward a correlation between the largest discrepancy in the total lower limb length and the percentage of the initial double support time in the affected lower limb ( $\mathrm{r}=-0.037$; $\mathrm{p}=0.074)$.

Of 20 children who were assessed with the WISC-IV cancellation subtest ${ }^{23}$, eight $(40 \%)$ showed hemineglect. Children with hemineglect had greater discrepancy between hand length and arm and thigh circumferences when compared with those without hemineglect (Table 5). Of 23 children who were evaluated with the WPPSI-R test ${ }^{23}, 12$ (52\%) had IQ score below 80. The average percentage of decrease in hand width was higher in the group with total IQ score below 80 ( $\mathrm{p}=0.044)$.

Children's average age at initiation of physical therapy was 9 months. At the time of the assessment, 18 patients had maintained physical therapy for more than 2 years (75\%). This variable could not be controlled because children had different backgrounds and great variation in type, frequency and intensity of physical therapy. We observed that early age at physical therapy initiation was associated with lower discrepancy in hand length $(\mathrm{p}=0.037)$.

Table 3. Distribution of side-to-side discrepancies*.

\begin{tabular}{|c|c|c|c|c|c|c|c|c|c|c|c|c|c|c|c|c|}
\hline \multirow[t]{2}{*}{ PT } & \multicolumn{2}{|c|}{ ULTL } & \multicolumn{2}{|c|}{$\mathrm{HL}$} & \multicolumn{2}{|c|}{ HW } & \multicolumn{2}{|c|}{ LLTL } & \multicolumn{2}{|c|}{$\mathrm{FL}$} & \multicolumn{2}{|c|}{$A C$} & \multicolumn{2}{|c|}{$\mathrm{TC}$} & \multicolumn{2}{|c|}{$\mathrm{CC}$} \\
\hline & DIF & $\%$ & DIF & $\%$ & DIF & $\%$ & DIF & $\%$ & DIF & $\%$ & DIF & $\%$ & DIF & $\%$ & DIF & $\%$ \\
\hline 1 & 1 & 2.1 & 1 & 8 & 0 & 0 & 1.5 & 3.1 & 1 & 6 & 0.5 & 2.4 & 0 & 0 & 1 & 4.2 \\
\hline 2 & 0 & 0 & 0.5 & 4.1 & 0.5 & 7.6 & 0 & 0 & 1 & 5.7 & 2 & 10.2 & 1 & 3 & 0.5 & 2.1 \\
\hline 3 & 3 & 6.5 & 1.2 & 10.2 & 0.5 & 8.3 & 0 & 0 & 0 & 0 & 2 & 10.5 & 1.5 & 4.1 & 2 & 8.6 \\
\hline 4 & 3 & 6.3 & 1.5 & 12 & 0.5 & 7.6 & 0.5 & 1 & 0 & 0 & 1 & 5.7 & 1 & 3 & 1 & 4.6 \\
\hline 5 & 0 & 0 & 1 & 8 & 0 & 0 & 1 & 2.2 & 0 & 0 & 1 & 5.8 & 1.5 & 4.9 & 2 & 8.6 \\
\hline 6 & 1.5 & 3.1 & 0.5 & 4 & 0.5 & 8.3 & 0.5 & 1 & 1.5 & 8.5 & 1.5 & 7.8 & 2 & 6.2 & 0.5 & 2.2 \\
\hline 7 & 1.5 & 3.7 & 0.9 & 8.2 & 0.5 & 8.3 & 1 & 2.4 & 1 & 6.2 & 1 & 5.2 & 0.5 & 1.4 & 0.5 & 2.2 \\
\hline 8 & 0.2 & 0.4 & 0.5 & 4.3 & 0 & 0 & 0 & 0 & 0 & 0 & 0 & 0 & 0 & 0 & 0 & 0 \\
\hline 9 & 1.8 & 3.9 & 0.7 & 5.7 & 0.7 & 11.2 & 1 & 2.1 & 1.7 & 9.6 & 1 & 5.8 & 2 & 6.6 & 1 & 4.7 \\
\hline 10 & 0.5 & 1.1 & 1.5 & 12.5 & 0.5 & 8.3 & 1 & 2.1 & 1.1 & 6.5 & 1.2 & 6 & 1.5 & 4.1 & 0.5 & 2 \\
\hline 11 & 1 & 2.3 & 1 & 9 & 0 & 0 & 0 & 0 & 1.1 & 6.9 & 1.2 & 7.8 & 1.5 & 5 & 0.9 & 4.5 \\
\hline 12 & 0.5 & 1.1 & 0.2 & 1.7 & 0 & 0 & 0 & 0 & 1 & 6.2 & 1 & 5.2 & 1 & 2.9 & 1 & 4.5 \\
\hline 13 & 1 & 2.1 & 0 & 0 & 0 & 0 & 1 & 2 & 0 & 0 & 0.5 & 2.7 & 0 & 0 & 0.5 & 2.2 \\
\hline 14 & 2.5 & 5.2 & 2 & 15.3 & 1 & 16.6 & 1 & 2.1 & 1.5 & 8.8 & 0.5 & 3 & 1 & 3.4 & 0.5 & 2.5 \\
\hline 15 & 1.5 & 3.6 & 1 & 8.6 & 0.5 & 8.3 & 1 & 2.3 & 1.5 & 9.6 & 1 & 5.5 & 0.5 & 1.6 & 1 & 4.7 \\
\hline 16 & 0.5 & 1.1 & 0.5 & 4.5 & 0.5 & 9 & 0 & 0 & 0.5 & 3.2 & 0.5 & 2.8 & 0.5 & 1.4 & 1 & 4.7 \\
\hline 17 & 2 & 4.7 & 1.7 & 15.45 & 1.2 & 20 & 1 & 2.3 & 1 & 6.6 & 1.5 & 8.3 & 1 & 3.2 & 1.5 & 6.9 \\
\hline 18 & 0.5 & 1.2 & 0.5 & 4.7 & 0.3 & 5.4 & 2 & 4.4 & 0.5 & 3.2 & 2 & 11.1 & 1 & 3.3 & 1.5 & 7.5 \\
\hline 19 & 3 & 6.6 & 2 & 16.66 & 0.5 & 8.3 & 1 & 2.1 & 0.2 & 1.1 & 2 & 10.5 & 1 & 3.1 & 1 & 4.3 \\
\hline 20 & 1 & 2.6 & 0.3 & 2.8 & 0.5 & 8.3 & 0 & 0 & 1 & 6.4 & 1 & 5.7 & 0.5 & 1.6 & 0.8 & 3.8 \\
\hline 21 & 1 & 2.1 & 0.8 & 6.2 & 0 & 0 & 0 & 0 & 0.5 & 2.7 & 2 & 11.1 & 0.5 & 1.5 & 1.5 & 6.6 \\
\hline 22 & 0.5 & 1.1 & 0.7 & 6 & 0.5 & 8.3 & 0 & 0 & 0.9 & 5.8 & 0.5 & 2.9 & 0 & 0 & 0.5 & 2.5 \\
\hline 23 & 0 & 0 & 0.5 & 4.3 & 0 & 0 & 2 & 4.3 & 0.5 & 2.9 & 1 & 5.5 & 1.5 & 4.2 & 0.5 & 2.1 \\
\hline 24 & 1.5 & 3 & 0.5 & 4 & 0 & 0 & 0 & 0 & 0 & 0 & 1 & 5.8 & 0 & 0 & 0 & 0 \\
\hline
\end{tabular}

PT: patient; DIF: difference; ULTL: upper limb total length; HL: hand length; HW: hand width; LLTL: lower limb total length; FL: foot length; AC: arm circumference; TC: thigh circumference; CC: calf circumference; \%: percentage compared with the normal side. ${ }^{\star}$ The differences are reported in centimeters and as percentages when compared with the normal side for each patient. 
Table 4. Correlations between side-to-side discrepancies and muscle strength, UPRS, GMFM and PEDI Scores.

\begin{tabular}{|c|c|c|c|c|}
\hline \multicolumn{2}{|l|}{ Correlation } & \multirow[t]{2}{*}{$n$} & \multirow[t]{2}{*}{$\mathrm{R}$} & \multirow[t]{2}{*}{$\mathrm{p}$} \\
\hline Muscle Strength & Discrepancy & & & \\
\hline \multicolumn{5}{|l|}{ Proximal Upper limb } \\
\hline & DIF HW & 23 & -0.43 & 0.042 \\
\hline & $\% \mathrm{HW}$ & 23 & -0.48 & 0.022 \\
\hline \multicolumn{5}{|l|}{ Distal lower limb } \\
\hline & $\% \mathrm{FL}$ & 23 & -0.39 & 0.066 \\
\hline & $\% \mathrm{TC}$ & 23 & -0.79 & 0.000 \\
\hline \multicolumn{5}{|l|}{ Total lower limb } \\
\hline & $\% \mathrm{FL}$ & 23 & -0.38 & 0.074 \\
\hline & $\% \mathrm{TC}$ & 23 & -0.80 & 0.000 \\
\hline \multicolumn{5}{|l|}{$\begin{array}{l}\text { Total upper and } \\
\text { lower limbs }\end{array}$} \\
\hline & $\% \mathrm{FL}$ & 23 & -0.49 & 0.017 \\
\hline & $\% \mathrm{TC}$ & 23 & -0.62 & 0.002 \\
\hline \multicolumn{5}{|l|}{ UPRS } \\
\hline & DIF ULTL & 24 & -0.80 & $<0.001$ \\
\hline & $\%$ ULTL & 24 & -0.78 & $<0.001$ \\
\hline & DIF HL & 24 & -0.56 & 0.004 \\
\hline & $\% \mathrm{HL}$ & 24 & -0.50 & 0.012 \\
\hline & DIF HW & 24 & -0.55 & 0.005 \\
\hline \multicolumn{5}{|l|}{ GMFM } \\
\hline \multicolumn{5}{|l|}{ Dimension A } \\
\hline & DIF_ULTL & 24 & -0.53 & 0.007 \\
\hline & \%_ULTL & 24 & -0.54 & 0.006 \\
\hline & DIF_HL & 24 & -0.62 & 0.001 \\
\hline & \%_HL & 24 & -0.61 & 0.001 \\
\hline & DIF_HW & 24 & -0.39 & 0.061 \\
\hline & \%_HW & 24 & -0.41 & 0.048 \\
\hline \multicolumn{5}{|l|}{ Dimension B } \\
\hline & DIF_ULTL & 24 & -0.44 & 0.030 \\
\hline & \%_ULTL & 24 & -0.45 & 0.027 \\
\hline \multicolumn{5}{|l|}{ Dimension C } \\
\hline & DIF_ULTL & 24 & -0.39 & 0.061 \\
\hline & \%_ULTL & 24 & -0.39 & 0.060 \\
\hline & DIF_HL & 24 & -0.41 & 0.048 \\
\hline & DIF_HW & 24 & -0.40 & 0.054 \\
\hline & \%_HW & 24 & -0.39 & 0.059 \\
\hline \multicolumn{5}{|l|}{ Dimension D } \\
\hline & DIF_HL & 24 & -0.40 & 0.049 \\
\hline & \%_HL & 24 & -0.39 & 0.057 \\
\hline & \%_FL & 24 & -0.41 & 0.048 \\
\hline \multicolumn{5}{|l|}{ PEDI - Mobility } \\
\hline Caregiver Assistance & DIF FL & 24 & -0.47 & 0.019 \\
\hline Caregiver Assistance & $\% \mathrm{FL}$ & 24 & -0.45 & 0.028 \\
\hline \multicolumn{5}{|l|}{ GAIT ANALYSIS } \\
\hline$\%$ IDSupport & DIF LLTL & 24 & -0.037 & 0.074 \\
\hline \multicolumn{5}{|c|}{$\begin{array}{l}\text { Spearman Correlation Coefficient; Dif: difference; \%: percentage com- } \\
\text { pared with the normal side; ULTL: upper limb total length; LLTL: lower } \\
\text { limb total length; HL: hand length; HW: hand width; FL: foot length; } \\
\text { TC: thigh circumference; UPRS: upper limb physician's rating scale; } \\
\text { GMFM: Gross motor function measure; PEDI: pediatric evaluation } \\
\text { disability inventory; Gait Analysis: Two-dimensional gait analysis; \% } \\
\text { IDS: percentage of time of initial double support. }\end{array}$} \\
\hline
\end{tabular}

\section{DISCUSSION}

This study was designed to evaluate side-to-side discrepancies in children with HCP, and investigate the association of these discrepancies with different factors potentially related to impaired function, and degree of activity and social participation.

Findings from our study show that growth discrepancy is more important in children with lower range of active and passive wrist extension, lower muscle strength, right side involvement, hemineglect and increased spasticity. We have also demonstrated an association between greater discrepancy and worst function in both upper and lower limbs.

The goals of a management program for children with HCP should include promotion of function, increase in developmental capabilities and focus on participation ${ }^{1}$. Hand function is one of the main problems in these children $^{16}$, and has been associated with growth impairment on the affected side. In hemiplegia, the possibility of comparing the sides of the body allows the study of the influence of non-nutritional factors on growth while excluding aspects related to the disease such as malnutrition and endocrine factors. It also eliminates other potential biases, including gender, race, parental height and pubertal status ${ }^{3,5,7}$.

Demir et al. ${ }^{3}$ reported in children with HCP significant differences in measurements of the upper limbs independent of spasticity. In contrast, we found that greater spasticity in the upper limbs was related to greater side-to-side discrepancies when considering the total upper limb length, hand length and the width of the palm of the hand. These data suggest that spasticity is an important factor for muscle growth. Some authors report that muscle growth is affected by increased muscle tone in children with hypertonia ${ }^{24}$. Fridén and Lieber ${ }^{25}$ demonstrated structural changes in spastic muscles, including shorter fibers and more rigid cells. Although these authors observe that spasticity is multifactorial and neurological in origin ${ }^{25}$, the muscles affected undergo substantial structural changes.

Demir et al. $^{3}$ also reported major discrepancies associated with decreased function on the affected hand. However, motor function of the upper limb was not related with greater discrepancy in bone length or circumference, which led the authors to question the sensitivity of the scale used in their study.

A study by Stevensen et al. ${ }^{7}$ used the Quality of Upper Extremity Skills Test (QUEST) to show a significant correlation between greatest functional impairment and largest discrepancy of the upper involved limb. In a study by Uvebrant ${ }^{2}$, hand function was significantly decreased in 53\% of the children and was also associated with a relatively larger dis- 
Table 5. Correlation between side-to-side discrepancy and presence of hemineglect.

\begin{tabular}{lccccccrr}
\hline Hemineglect & Discrepancy & $\mathrm{n}$ & Mean & Median & Minimum & Maximum & SD & $\mathrm{p}$ \\
\hline Yes & DIF_HL & 14 & 0.65 & 0.50 & 0.00 & 1.50 & 0.39 & 0.55 \\
No & DIF_HL & 8 & 1.15 & 1.10 & 0.50 & 2.00 & 0.042 \\
Yes & DIF_AC & 14 & 0.98 & 1.00 & 0.00 & 2.00 & 0.54 & 0.020 \\
No & DIF_AC & 8 & 1.53 & 1.50 & 1.00 & 2.00 & 0.44 & 0.020 \\
Yes & DIF_TC & 14 & 0.68 & 0.50 & 0.00 & 2.00 & 0.61 & 0.020 \\
No & DIF_TC & 8 & 1.31 & 1.50 & 0.50 & 2.00 & 0.46 & 0.00 \\
Yes & \%_HL & 14 & 5.54 & 4.60 & 0.00 & 12.00 & 3.25 \\
No & \%_HL & 8 & 9.66 & 9.10 & 4.00 & 16.66 & 4.88 & 0.070 \\
Yes & \%_AC & 14 & 5.42 & 5.60 & 0.00 & 11.10 & 2.96 \\
No & \%_AC & 8 & 8.19 & 8.05 & 5.50 & 11.10 & 2.30 & 0.016 \\
Yes & \%_TC & 14 & 2.13 & 1.60 & 0.00 & 6.60 & 1.99 & \\
\hline
\end{tabular}

Non-Parametric Mann-Whitney Test; Dif: difference; \%: percentage compared with the normal side; HL: hand length; AC: arm circumference; TC: thigh circumference; SD: standard deviation.

crepancy. The author suggests that this percentage could be even higher if the function were measured with a scale that assesses object manipulation or by using methods proposed by Brown et al. ${ }^{16}$. In our study, we found a correlation between a higher score in the UPRS and lower side-to-side discrepancy ${ }^{17}$. The UPRS ${ }^{17}$ evaluates ten movements involved in the functional use of the hand. The distribution of these scores allows identification of the importance of the functional use of the hand in its growth. However, Uvebrant ${ }^{2}$ mentioned the presence of confounding factors when, for example, the largest discrepancy is related to upper limb stereognosis deficits. In our study, the association between greatest side-to-side discrepancy and function was determined using scales that also assess gross motor function. These data suggest that several factors are involved in both the genesis and the adaptation to disability.

We observed an association between left handedness and decreased side-to-side discrepancy, specifically in the measurements of arm and calf circumferences. Children with hemineglect had greater discrepancies in hand length, as well as arm and thigh circumferences. These findings point to the greater importance of perception in relation to handedness, as suggested by Katz et al. ${ }^{26}$. Hemineglect is a recognized condition that imposes great impairment in adults ${ }^{26}$, and ours is the first study to address hemineglect in children with HCP.

Immobility, reduced weight-bearing stimulation, disuse and low blood flow in the involved side are factors that may indirectly affect growth ${ }^{7,9}$. However, the association between age at initiation of physical therapy and lower discrepancy in hand length suggests that these factors can be mitigated by early intervention. Physical therapy for hemiplegic patients is directed towards stimulating active use of the involved side. As for the upper limb, physical therapy aims at developing the functions of reaching and weight bearing. For example, a stage that requires intense stimulation in early infancy is the crawling phase, since it bears weight on the affected upper limb. Children with HCP tend to move from the sitting position by dragging themselves using the unaffected upper limb. Crawling can be extremely beneficial since it also stimulates the correct posture using outstretched hand support, and strengthens the support of the upper limbs, allowing the child to move with the entire body in coordination. According to McDaid et al. ${ }^{27}$, abnormal muscle function can lead to lack of mechanical stress which is critical for healthy and early skeletal development.

Roberts et al. ${ }^{5}$ showed that in the upper limbs, bone maturation on the affected side was significantly lower when compared with the unaffected limb. They suggest that there may be an association between the functional use of the extremities and bone maturation. Results from our study suggest that functional use of the extremities may be related to limb growth. Since our study is cross-sectional, longitudinal studies are needed to evaluate the impact of physical therapy intervention on paretic limbs.

Considering that hand function is one of the most important problems in children with $\mathrm{HCP}^{16}$ and that it has been related to growth impairment on the affected side, the association we found between IQ and side-to-side hand discrepancy draws attention to the relationship between early age at initiation of physical therapy and lower discrepancy. These data suggest that the active use of the hand can be related to either intrinsic (cognitive) or extrinsic (physical therapy) factors.

In contrast to previous studies, we evaluated the impact of discrepancy on lower limb function. Pellegrino and Dormans $^{28}$ reported that discrepancies in the length of the limbs may result in significant gait difficulties and orthopedic problems. In our study, decreased muscle strength in the lower limb was associated with greater discrepancies in thigh circumference and foot length. In addition, we found a trend toward a correlation between the discrepancy in lower limb length and the percentage of the initial double support time in the affected lower limb. It is possible that the impairment in function on the lower limb may be due in part to the creation of a "short lever" in the involved lower limb and foot. Normal ambulation depends on adequate and appropriate forces acting through lever arms of appropriate sizes in stable joints ${ }^{29}$. Gage and Schwartz ${ }^{29}$ reported that in conditions such as cerebral palsy, force reactions from both 
the muscles and the ground are neither appropriate nor adequate. This arises from muscle contractures, poor body segment balance and/or positioning, poor selective motor control, and abnormal or short bone lever arms.

In a previous study by our group, which analyzed gait in the same cohort that participated in the present study ${ }^{22}$, we found an association between the lowest percentage of double support time in the involved limb with decreased muscle strength. We observed that these two variables were related to greater discrepancy in the involved limb, reinforcing the involvement of several factors in both the genesis and adaptation to disability. In the same way that hand function is highly dependent on sensory-motor integration, other factors not measured in our study, such as weight distribution on a force platform in the standing position, may be helpful in clarifying growth discrepancies and function in the lower limb.

We also found that smaller lower limb discrepancy was related to a higher score in the dimension $\mathrm{D}$ of the GMFM- $88^{18}$ which evaluates items in the standing position, as well as higher scores in the PEDI ${ }^{19}$, which reflects greater independence in daily activities related to mobility with less need for caregiver assistance. The PEDI scale has been pointed out as a measure of social participation ${ }^{19}$ which gives much more importance to the association between discrepancy in foot length and independence on the mobility area. This situation could perhaps be another example of what Wright et al. ${ }^{30}$ have mentioned, "If the foot size increases (body functions and structures), to what extent might stair climbing abilities (activity) improve, and what might happen to the child's abilities to go shopping with friends at a nearby shopping mall (participation)?" We certainly need to continue investigating the associations between growth, function, degree of activity and social participation of children with HCP, as well as direct rehabilitation programs to help them optimize performances in these areas.

\section{Acknowledgments}

We would like to thank Márcia Olandoski for her careful statistical analysis.

\section{References}

1. Rosenbaum P. Cerebral palsy: what parents and doctors want to know. BMJ 2003;326:970-974.

2. Uvebrant P. Hemiplegic cerebral palsy: aetiology and outcome. Acta Paediatr Scand 1988;345(Suppl.):S50-S86.

3. Demir SO, Oktay F, Uysal H, Selçuk B. Upper extremity shortness in children with hemiplegic cerebral palsy. J Pediatr Orthop 2006;26:764-768.

4. Zonta MB, Agert F, Muzzolon SRB, et al. Growth and anthropometry in hemiplegic cerebral palsy patients. Rev Paul Pediatr 2009;27:416-423.

5. Roberts CD, Vogtle L, Stevenson RD. Effect of hemiplegia on skeletal maturation. J Pediatr 1984;125:824-828.

6. Kong CK, Tse PWT, Lee WY. Bone age and linear skeletal growth of children with cerebral palsy. Dev Med Child Neurol 1999:41:758-765.

7. Stevensen RD, Roberts CD, Vogtle L. The effects of non-nutritional factors on growth in Cerebral Palsy. Dev Med Child Neurol 1995;37:124-130.

8. Van Heest AE, House J, Putnam M. Sensibility deficiencies in the hands of children with spastic hemiplegia. J Hand Surg Am 1993;18:278-281.

9. World Health Organization. International Classification of Functioning, Disability and Health. Geneva: World Health Organization, 2001.

10. Rempel GR, Colwell SO, Nelson RP. Growth in children with cerebral palsy fed via gastrostomy. Pediatrics 1988;82:857-862.

11. Stevensen RD, Hayes RP, Cater LV, Blackman JA. Clinical correlates of linear growth in children with cerebral palsy. Dev Med Child Neurol 1994;36:135-142.

12. Palisano R, Rosenbaum P, Walter $\mathrm{S}$, et al. Development and reliability of a system to classify gross motor function in children with cerebral palsy. Dev Med Child Neurol 1997;39:214-223.

13. Hall JG, Froster-Iskenius UG, Allanson JE. Handbook of normal physical measurements. Oxford: Medical Publications, 1989.

14. Ashworth, B. Preliminary trial of carisoprodol in multiple sclerosis. Practitioner 1964;192:540-542.
15. Medical Research Council, Aids to the examination of the peripheral nervous system. Memorandum n.45, Her Majesty's Stationery Office, London, 1981.

16. Brown JK, Van Rensburg F, Walsh G, et al. A neurological study of hand function of hemiplegic children. Dev Med Child Neurol 1987;29:287-304.

17. Graham HK, Aoki KR, Autti-Rämö I, et al. Recommendations for use of botulinum toxin type $A$ in management of cerebral palsy. Gait Posture 2000;11:67-79.

18. Russell DJ, Rosenbaum PL, Cadman DT, et al. The gross motor function measure: a mean to evaluate the effects of physical therapy. Dev Med Child Neurol 1989;31:341-352.

19. Haley SM, Coster WJ, Ludlow LH, et al. Pediatric evaluation of disability inventory: development, standartization and administration manual. Boston: New England Medical Center, 1991:1-300.

20. Klingels K, Jaspers E, Van de Winckel A, et al. A systematic review of arm activity measures for children with hemiplegic cerebral palsy. Clin Reab 2010:24:887-900.

21. Koman LA, Brashear A, Rosenfeld S, et al. Botulinum toxin type A neuromuscular blockade in treatment of equines foot deformity in cerebral palsy: a multicenter, open label clinical trial. Pediatrics 2001;108:1062-1071.

22. Zonta MB, Ramalho Junior A, Camargo RMR, Dias FH, Coutinho dos Santos LH. Two-dimensional analysis of gait asymmetry in spastic hemiplegia. Einstein 2010;8:343-849.

23. Wechsler D. Wechsler Preschool and Primary Scale of Inteligence Revised David Wechsler. The Psychological Corporation Harrourt Brace Jovanovich, 1989.

24. Eames NWA, Baker R, Hill N, et al.The effect of botulinum toxin A on gastrocnemius length: magnitude and duration of response. Dev Med Child Neurol 1999;41:226-232.

25. Fridén J, Lieber RL. Spastic muscle cells are shorter and stiffer than normal cells. Muscle Nerve 2003;26:157-164. 
26. Katz N, Hartman-Maeir A, Ring H, Soroker N. Functional disability and rehabilitation outcome in right hemisphere damaged patients with and without unilateral spatial neglect. Arch Phys Med Rehabil 1999;80:379-384

27. McDaid PJ, Kozin SH, Thoder JJ, Porter ST. Upper extremity limblength discrepancy in braquial plexus palsy. J Pediatr Orthop 2002;22:364-366.

28. Pellegrino L, Dormans JP. Definitions etiology and epidemiology of cerebral palsy. In: Dormans JP, Pellegrino L. (Ed.). Caring for children with cerebral palsy. Baltimore: Paul H Brooks;1998:3-30.
29. Gage, JR, Schwartz, M. Pathological Gait and lever-arm dysfunction. In: Gage JR (Ed). The treatment of gait problems in cerebral palsy. London: Mac Keith Press, 2004:80-204.

30. Wright FV, Rosenbaum PL, Goldsmith CH, Law M, Fehlings DL. How do changes in body function and structures, activity and participation relate in children with cerebral palsy? Dev Med Child Neurol 2008;50:283-289. 